\title{
NOTAS EN TORNO A LOS DESAFÍOS PRÁCTICOS DE LA LIBERTAD DEL CIENTÍFICO EN LA SOCIEDAD CONTEMPORÁNEA Hugo S. Ramírez García*
}

\section{Introducción: la libertad del científico como 'inmunidad ética'}

La definición del contenido de la libertad del científico para realizar investigaciones y llevar a cabo sus hipótesis es una cuestión problemática de importancia mayúscula para la reflexión ética de nuestro tiempo. Ello porque tal definición supone no sólo el establecimiento de límites a la acción pública sobre la actividad concreta del científico, sino el señalamiento de fronteras para la reflexión práctica misma. En efecto, el desarrollo científico, o mejor tecno-científico, reclama hoy un coto vedado que minimiza la cali-

* El autor es doctor en Derecho por la Universidad de Valencia. Actualmente, investigador de tiempo completo en la Facultad de Derecho de la Universidad Panamericana, Ciudad de México. ficación ética de los actos que realiza el hombre de ciencia. Se trata de uno de los valores del denominado 'humanismo secular' que en voz de Paul Kurtz tiene como función: resistir los esfuerzos irracionales que, ejerciendo una tiranía sobre la mente del hombre, buscan evitar los avances tecnológicos y científicos. ${ }^{1}$

Esta pretensión está ligada al ideal antropocéntrico de una humanidad liberada de todo tipo de sujeción fundamental. De esta forma, la libertad a la que aspira la ciencia hace referencia, sobre todo, a la capacidad para trascender límites como una clara manifestación del ideal que la Modernidad intentará realizar por medio de la negación filosófica

${ }^{1}$ Cfr. Kurtz, P., "Una declaración humanista secular", en Revista Peruana de Filosofia Aplicada. Documento consultado en: ww.geocities. com/Athens/Olympus/9234/humsec.html. 
de la naturaleza. Ésta será identificada como la fuente más relevante de límenes, materiales y éticos, para la actividad humana. Frente a ella la humanidad desarrollará una actitud que comporta la afirmación de la manipulabilidad total de la naturaleza, incluida la propia, así como la artificialización como evidencia privilegiada de lo humano. $^{2}$

Expuesto en otros términos, la liberación moderna del hombre, a la cual está directamente asociada la definición del contenido de la libertad del científico, busca primordialmente el aumento de la capacidad de intervención y control del ser humano sobre la naturaleza y la sociedad, a fin de llevar a cabo el ideal de la autonomía plena. ${ }^{3}$

En lo que sigue, tendré como propósito:

Primero, explicar los componentes que han fortalecido la definición moderna del contenido de la libertad de la ciencia, asimilándola con la 'inmunidad ética'.

Segundo, identificar las consecuencias de tal asimilación.

Finalmente, esbozar algunos rumbos para la solución de los dilemas vinculados al fenómeno del poder de la ciencia, y sobre la ciencia.

${ }^{2}$ Cfr. S. Cotta, El hombre tolemaico. La crisis de la civilización tecnológica, 1977, Madrid, Rialp, p. 174.

${ }^{3} \mathrm{Cfr}$. A. Llano, El futuro de la libertad, 1985, Pamplona, EUNSA, p. 91.

\section{Factores que impulsan una noción de libertad como inmunidad ética}

Sin lugar a dudas, la fuerza con la que se pone de manifiesto el reclamo de la indemnidad ética para la ciencia, así como la dificultad para definir los contornos del problema que suscita, se explican por la convergencia y el entrelazamiento de múltiples argumentos, cada uno de ellos provenientes de diversas fuentes. Podemos identificar tres de ellas, desde las cuales se proponen los argumentos que justifican la asimilación de la libertad de la ciencia con una 'inmunidad ética', a saber: a) El estatuto moderno de la epistemología científica; b) La filosofía ética liberal, y c) Una teoría ética y del derecho de corte inmanentista. Analicemos cada uno de ellos brevemente.

a) Desde el estatuto de la epistemología científica destacan los argumentos asociados a la moderna vocación del científico y aquellos que resultan de la influencia de la ideología cientificista.

Respecto de la primera, no cabe duda que la vocación del científico revela los contornos del espacio dentro del cual aquél pretende llevar a cabo su labor y cumplir con los objetivos vocacionales. Efectivamente, la idea de vocación, que a su vez remite a la de sentido, es un 
presupuesto para comprender cuáles son las condiciones que exigiría una labor concreta, como por ejemplo, aquella que contribuye a la validación e incremento del conocimiento humano sobre la realidad.

En este orden de ideas, y siguiendo a Max Weber, es posible afirmar que la vocación del científico, configurada en el marco de la cultura moderna, se concreta en el mantenimiento de las expectativas que genera la convicción de que el desarrollo de la humanidad depende del progreso científico y tecnológico. Es decir, el leit motiv de la actividad del hombre de ciencia es cumplir las profecías de la ideología del progreso ilimitado e infinito. Tales promesas giran en torno al advenimiento de una situación generalizada de control artificial absoluto sobre los fenómenos naturales. Al mismo tiempo, es responsabilidad del científico construir una nueva expectativa que será colmada con un trabajo por venir, de tal manera que no se rompa, o se contradiga, la naturaleza ilimitada e infinita del progreso. ${ }^{4}$

${ }^{4}$ En palabras del propio Max Weber: "No podemos trabajar sin la esperanza de que otros han de llegar más allá que nosotros, en un progreso que, en principio, no tiene fin. Llegamos así al problema del sentido de la ciencia [...] ¿Por qué ocuparse de algo que, en realidad, no tiene ni puede tener nunca un fin? Una primera respuesta es la de que eso que se hace con una finalidad práctica o, en términos más amplios, técnica: para poder orientar nuestro comportamiento práctico en función de
Las notas que hemos apuntado acerca de la vocación del hombre de ciencia, en último término, parecen justificar una amplia libertad de movimientos para el científico, derivada del carácter efímero y transitorio de su actividad: ambos atributos sugieren la levedad ética de las labores científicas, toda vez que su sentido y valor descansan en un proceso intangible para el agente mismo, $\mathrm{y}$ cuyo desarrollo no controla.

Ahora bien, las expectativas que se configuran y confirmar por medio del desarrollo científico se transforman en fuente de sentido general para la sociedad en su conjunto a través de la ideología cientificista. El cientificismo, como también se le conoce, puede ser descrito como una postura filosófico-política, fundamentada en la convicción de que la humanidad tiene una vocación tecnológica. Esto es, el cientificismo admite como principio que el progreso tecnológico se ha convertido en una meta para la humanidad, en el sentido de su historia, el contenido de la labor cotidiana, la fuente de incontables beneficios. Como acertadamente expuso Hans Jonas:

Hoy la techne, en su forma de técnica moderna, se ha translas expectativas que la experiencia científica nos ofrece." M. Weber, El politico y el cientifico, 2001, Madrid, Alianza Editorial, trad. Francisco Rubio Llorente, p. 199. 
formado en un infinito impulso hacia delante de la especie, en su empresa más importante, en cuyo continuo progresar, que se supera a sí mismo hacia cosas cada vez más grandes, se intenta ver la misión de la humanidad, y cuyo éxito en lograr el máximo dominio sobre las cosas y los propios hombres, se presenta como la realización de su destino. ${ }^{5}$

Entre los efectos de la ideología cientificista destacan, en primer lugar, la reivindicación para la ciencia del monopolio de racionalidad, de la cual se deduce que sólo aquélla y la técnica resultante, creadas y poseídas por la categoría especial de los expertos, pueden resolver los problemas de la humanidad. Y en segundo, la exigencia de autonomía y amoralidad fundamentada en cierta autoridad 'misteriosa pero indiscutible', según expresión de Marcos Kaplan, a su vez vinculada precisamente al monopolio de racionalidad que reivindica para sí la ciencia en nuestro tiempo. ${ }^{6}$

Acudiendo una vez más al análisis de Marcos Kaplan sobre la ideología cientificista, ésta ha fomentado la configuración de un espacio autista

${ }^{5} \mathrm{H}$. Jonas, El principio de responsabilidad. Ensayo de una ética para la civilización tecnológica, 1995, Barcelona, Herder, trad. J. Fernández, p. 35-6.

${ }^{6}$ Cfr. M. Kaplan, Ciencia, sociedad y desarrollo, 1987, México, UNAM, p. 90 y s; la cita textual se toma de la página 95 . para la actividad del científico, ajeno a la reflexión práctica, en la medida en que ha propiciado el alejamiento de buena parte de la ciencia respecto de las realidades más vitales y significativas de lo humano. A su vez, tal distanciamiento provoca un desenfoque con relación al desarrollo humano y sus exigencias más auténticas, toda vez que lo identifica con el progreso incontrolado de la ciencia y de la técnica, convalidando un modelo social donde prevalecen la eficiencia, el consumo y la disipación de responsabilidades. ${ }^{7}$

b) Otro de los componentes básicos de la identificación de la libertad de la ciencia con la inmunidad ética se encuentra en el corazón de la filosofía ética liberal, sobre todo en las tesis que giran alrededor de la idea de libertad negativa. Ésta, según ha sido expuesto por Isaiah Berlin en su famosa conferencia Dos conceptos de libertad, consiste en la ausencia de interferencia en las acti-

${ }^{7}$ Cfr. ibid., p. 97. La disipación de la responsabilidad a la que hacemos referencia sería el resultado, según la opinión de René Dubos, de cierto interés y excitación públicos con relación al desarrollo científico que ofrece continuamente resultados espectaculares; se trata de una evasión o fuga de las dificultades de la vida cotidiana, de las responsabilidades presentes gracias al "rico material para soñar despiertos que todos los problemas de la humanidad puede ser resueltos por medio ciencia”. Dubos, R., Los sueños de la razón. Ciencia y utopías, 1996, México, FCE, trad. J. Almela, p. 125. 
vidades que, existencialmente, son más importantes para el hombre; es decir, aquellas mediante las cuales se realiza nuestro propio bien a nuestra manera. ${ }^{8}$

Es bien conocida la distinción de Berlin entre la 'libertad de', esto es, la libertad expuesta en términos negativos como no-interferencia, y la 'libertad para', o libertad positiva. En rigor, el sentido de la libertad auténticamente liberal correspondería según este autor a su vertiente negativa, ya que su contraparte tiende a ser interpretada como una forma de autodominio con base en una concepción dualista y no individualista del sujeto, situando fuera de éste los fines a los que 'libremente' adhiere su existencia. Para Berlin, y en general para la mayoría de los autores liberales, esta última interpretación de la libertad es una auténtica paradoja para las coordenadas individualistas: adoptar esta manera de pensar, conduce a

ignorar los deseos reales de los hombres [...] intimidarlos, oprimirlos y torturarlos en nombre y en virtud de sus verdaderos yos, con la conciencia cierta de que cualquiera que sea el verdadero fin del hombre [...] dicho fin tiene

${ }^{8}$ Cfr. I. Berlin, Cuatro ensayos sobre la libertad, 1998, Madrid, Alianza Editorial, trad. J. Bayón, p. 226. que identificarse con la libertad, la libre decisión de su verdadero yo, aunque frecuentemente esté oculto o desarticulado. ${ }^{9}$

En el plano que nos ocupa, y por razón de la gran influencia de la filosofía ética liberal en la sociedad de nuestro tiempo, la actividad de los científicos se ha incorporado a ese catálogo de situaciones en las que la intromisión de agentes diversos a los directamente implicados, ya sea en la definición de metas o la elección de medios para lograrlas, es un acto de coacción ilegítima. ${ }^{10}$

c) Finalmente, quisiera referirme a la aportación de la teoría ética y del derecho de corte inmanentista, o positivas, que igualmente sugieren una definición de libertad para la actividad científica caracterizada por un desenvolvimiento soberano. Ahora, la causa de la soberanía de la ciencia se concentra en dos argumentos vinculados a la naturaleza del deber ser atribuida por autores como Ernesto Garzón Valdés. Según este profesor de la Universidad de Manguncia, la ética es, a final de cuentas, un medio impotente para establecer límites deónticos al quehacer científico en general, y al tecnológico en particu-

${ }^{9}$ Ibid., p. 234.

${ }^{10}$ Cfr. F. Ovejero, La libertad inhóspita. Modelos humanos y democracia liberal, 2002, Barcelona, Paidós, p. 69-72. 
lar. Concretamente, Garzón Valdés hace referencia al problema de la incapacidad de la ética, tanto en su manifestación moral como jurídica para, de facto, controlar, dirigir $\mathrm{u}$ orientar las actividades humanas vinculadas directamente con el conocimiento científico y su aplicación. Las causas de tal impotencia están en la incoercibilidad de la moral, así como en la naturaleza reactiva del derecho, debido a su aplicación condicionada a la previa declaración de antijuridicidad. ${ }^{11}$

En definitiva, según esta postura, ante el vacío ético la razón humana se decanta hacia los contenidos de la racionalidad instrumental, dando un salvoconducto incondicionado a la labor científica y al imperativo tecnológico.

\section{Consecuencias de la identificación de la libertad como inmunidad ética}

Sin lugar a dudas las consecuencias de la equiparación entre la libertad para la labor científica y la inmunidad ética son varias, y entre ellas encontraremos algunas que incluso puedan ser consideradas positivas. Ahora, no obstante, dirigiré mi aten-

${ }^{11}$ Cfr. E. Garzón, “¿Qué puede ofrecer la Ética a la Medicina?”, en Isonomía, nº 8, 1998, México, p. 26-7. ción a algunas de ellas que tengo por más relevantes, considerando los graves resultados negativos que propician, además de la coincidencia que hay entre ellas y que apunta hacia el debilitamiento de la praxis a favor de la poiesis. ${ }^{12}$ Concretamente me referiré a diversas situaciones donde se pone de manifiesto una justificación de la violencia asociada al allanamiento del camino para el progreso tecnocientífico, mediante el bloqueo de la calificación práctica de su desarrollo.

a) La garantía del desarrollo ininterrumpido de la ciencia propicia

${ }^{12}$ Como lo explica Gadamer, en los tiempos que corren se verifica un debilitamiento de la natural inteligencia y responsabilidad de pensamiento que califican éticamente a las conductas humanas. Esto a causa del crecimiento de la anomia que tiende a consolidarse alrededor de la actividad del científico, respaldada, a su vez, en la creciente gestión de la vida cotidiana organizada científicamente. Cfr., H. Gadamer, La herencia de Europa, 1990, Barcelona, Península, trad. P. Giralt, p. 97. Una opinión análoga la encontramos en Ciencia y técnica como ideología, de J. Habermas. Ahí, este autor describe cómo la racionalización de la acción, la inmersión de la tecnociencia en la vida cotidiana, provoca la disminución del interés práctico tras el afán por la ampliación del poder de disposición de la técnica; es decir, los diversos objetivos y necesidades que podrían dar lugar a la acción comunicativa tienden a desaparecer, eclipsados por un objetivo único: el aumento de la capacidad tecnológica de la sociedad, a cuyas espaldas se encuentra el bienestar individual y colectivo de la sociedad. Así aparece que la acción en la sociedad está encauzada cada vez más por estímulos que por normas. Cfr. J. Habermas, Ciencia y técnica como 'ideología', 1986, Madrid, Tecnos, trad., M. Jiménez, p. 53-108. 
un desenfoque en la dimensión temporal del acto humano, privilegiando al instante, a lo inmediato. Los actos sometidos a esta reducida coordenada temporal, aunque puedan ser violentos, escapan al juicio ético por razón de su utilidad. Es decir, la necesidad se manifiesta como una forma de sujeción asociada al tiempo presente, y justifica la realización de cualquier tipo de acto que logre satisfacerla. O como lo explicó Sergio Cotta:

$\mathrm{La}$ (presunta) productividad de la violencia ejercida sobre la naturaleza abre el camino a la violencia productora de una nueva historia, caracterizada por la liberación de la servidumbre del tiempo y de los condicionamientos materiales en el infinito desatarse de la fantasía creadora. ${ }^{13}$

${ }^{13}$ S. Cotta, El hombre tolemaico..., op. cit., p. 170-1. En El principio de responsabilidad, Hans Jonas nos ofrece un párrafo que ayuda a explicar el contexto en el que se da el instantaneísmo ético al que venimos haciendo referencia: se trata de la política de la utopía. Textualmente, Jonas expone: "Sólo con el moderno progreso -como hecho y como idea-surge la posibilidad de concebir todo lo anterior como paso previo hacia lo actual, y todo lo actual como paso previo hacia lo futuro. Cuando esta concepción-que, en cuanto ilimitada, no entiende ningún estado de cosas como definitivo y le deja a cada uno su inmediatez orientada al presente-se asocia a una escatología secularizada que señala un lugar finito en el tiempo al Absoluto definido como intramundano, apareciendo así la idea de un dinamismo teleológico del proceso que conduce al orden definitivo, cuando eso ocurre se dan las condiciones teóricas para la política
Es preocupante que lo inmediato, como umbral temporal de la responsabilidad, choca con la extensión, también temporal, de los efectos vinculados a la aplicación de tecnociencia.

b) Por otro lado, la ausencia de unos límites para la actividad científica provoca la emergencia de lo que Alejandro Llano denomina como tecnosistema con poder determinante: una situación gobernada casi enteramente por la lógica del imperativo tecnológico. Éste sentencia como un deber llevar a cabo aquello que tecnológicamente es posible. Bajo estas circunstancias, el consorcio cienciatécnica se configura, frecuentemente, en una fuente de opresión, toda vez que el imperativo tecnológico

impone sus propias exigencias, sometidas a parámetros valorativos de índole material y cuantitativa. Y los fines cualitativos del hombre mismo parecen carecer de fuerza si se comparan con la implacable secuencia del progreso técnico. ${ }^{14}$

utópica. Presupone una concepción del acontecer humano que mediatiza radicalmente todo lo anterior, esto es: lo condena a la provisionalidad, lo despoja de su valor propio o, en el mejor de los casos, lo convierte en vehículo para la consecución del auténtico valor que está por venir, hace de él un medio para el fin futuro, único válido.” $\mathrm{H}$. Jonas, $E l$ principio de responsabilidad..., op. cit., p. 47.

${ }^{14}$ A. Llano, El futuro de la libertad, op. cit., p. 94. 
La creencia de que todo acontecimiento humano es posible, previsible y que no habría razón para prohibirlo, advierte Hannah Arendt, podría acarrear el gravísimo riesgo de originar el movimiento que caracteriza al totalitarismo, es decir, aquel identificado con la voluntad móvil o la revolución permanente que se contrapone al límite y a la estabilidad, y para lo cual llega al uso de la violencia: a medios esencialmente inmorales, que recurren a la opresión para convertir lo plural en $u n o,{ }^{15} \mathrm{y}$ transforman la co-acción, o acción de muchos, en coacción. ${ }^{16}$

c) Finalmente, Jesús Ballesteros ha mostrado que, en algún sentido, la inmunidad ética de la ciencia conduce a la legitimación de la indiferencia en relación con el otro. En este caso, la libertad entendida como independencia justifica el desprecio y marginación política hacia los que no coinciden y no siguen the best one way avalando, así mismo, el olvido

15 “(Aunque en este supuesto) cada uno de los ciudadanos retuviera algún derecho en el manejo de los asuntos públicos, advierte nuestra autora, en conjunto actuarian como un solo hombre sin tener siquiera la posibilidad de disensión interna, menos aún la lucha de facciones: mediante el gobierno, los muchos se convierten en uno en todo aspecto, excepto en la aparición física." H. Arendt, La condición humana, 1993, Barcelona, Paidós, trad. R. Gil, p. 244.

${ }^{16}$ H. Arendt, Crisis de la República, 1973, Madrid, Taurus, trad., G. Solana, p. 144. e incluso el deseo de dominio sobre el otro, encarnado en los peor situados. ${ }^{17}$ Bajo este contexto, algunas voces han denunciado la emergencia de un neocolonialismo de corte intelectual que, entre otras cosas, fomenta una distinción tajante e irreal entre el conocimiento y la ignorancia con resultados discriminatorios. ${ }^{18}$

\section{Itinerarios hacia una reformulación filosófica de la libertad}

Creo que buena parte de los dilemas que suscita el desarrollo científico y tecnológico, y de las posibilidades de su calificación ética, pasan por un enriquecimiento de la idea de responsabilidad que robustezca al razonamiento práctico en una sociedad como la nuestra: donde la naturaleza global y a veces irrever-

${ }^{17}$ Cfr. J. Ballesteros, Postmodernidad: decadencia o resistencia, Madrid, Tecnos, p. 43-6.

${ }^{18}$ Una distinción tal entre el conocimiento y la ignorancia opera como una barrera para excluir del amplio ámbito del conocimiento a personas que orientan sus formas de saber de manera distinta a los moldes de la ciencia moderna, así como a sus discursos, considerados bajo este tenor como arcaicos. En este sentido, afirma Vandana Shiva, "el reduccionismo gnoseológico no es otra cosa sino una disminución de la capacidad humana para conocer la realidad, al excluir a otros conocedores y otros conocimientos". V. Shiva, Monocultures of the mind. Perspectives on biodiversity and biotechnology, 1993, Londres, Zed Books/Third Wold Network, p. 10. 
sible de los efectos derivados del funcionamiento de los sistemas que la componen, ${ }^{19}$ inhabilita al concepto tradicional de responsabilidad para hacernos cargo de ellos desde un punto de vista ético.

Un primer paso en este sentido es el distanciamiento del contenido y consecuencias éticas de la libertad, respecto de los contenidos y consecuencias éticas de la soberanía o inmunidad ética. Se trata de una renovación filosófica de la libertad en la que puede ser de gran provecho tener en cuenta el pensamiento de autores como Hannah Arendt; sobre todo por aquellas de sus reflexiones que giraron en torno a la posibilidad

${ }^{19}$ Desde una perspectiva sociológica, Ulrich Beck ha descrito esta situación con el concepto sociedad del riesgo. Dicho sintéticamente, la sociedad del riesgo hace referencia a una fase de desarrollo de la sociedad moderna en la que, a través de la dinámica de producción y cambio que la caracteriza, la generación de riesgos escapa, cada vez en mayor proporción, a las instituciones de control y protección con los que contaría la sociedad industrial. Entre otros efectos, la sociedad del riesgo supone, por un lado, que los conflictos típicos de distribución de los bienes sociales, sean superpuestos por los conflictos de distribución de los daños colectivamente producidos, precisamente para obtener los antedichos bienes sociales; y por otro, que la libertad de acción de los individuos los trascienda, en el sentido de que, con motivo de la elevada complejidad de la sociedad moderna, no pueden encontrar razón de la inevitabilidad de las decisiones, ni considerarse responsables de sus posibles consecuencias. Cfr. U. Beck, "Teoría de la sociedad del riesgo", en J. Beriain (comp.), Las consecuencias perversas de la Modernidad, 1996, Barcelona, Anthropos, p. 201-5. de definir a la libertad como capacidad de relación interpersonal, de inclusión, de coparticipación.

Concretamente, en esta oportunidad voy a ocuparme sólo de algunos componentes del concepto arendtiano de libertad como un atributo del ser, no como una mera posesión. Textualmente nuestra autora señala:

Los hombres son libres, es decir, algo más que meros poseedores del don de la libertad, mientras actúan; ni antes ni después, porque ser libre $\mathrm{y}$ actuar son la misma cosa. ${ }^{20}$

La diferencia más relevante entre una concepción de la libertad como posesión y otra que la define como efecto del ser personal, es que la segunda no admite un ejercicio de la misma en términos de privacidad. Como lo explicó la propia Arendt, la libertad es una consecuencia de ser humano, y

en condiciones humanas, que están determinadas por el hecho de que en la Tierra no vive un hombre sino los hombres, la libertad y la soberanía son tan poco idénticas que ni siquiera pueden existir simultáneamente [...] Si los hombres quieren ser libres,

${ }^{20} \mathrm{H}$. Arendt, Entre el pasado y el futuro. Ocho ejercicios sobre la reflexión política, 1996, Barcelona, Península, trad., A. Poljak, p.165. 
deben renunciar precisamente a la soberanía. ${ }^{21}$

Dicho con otros términos, la libertad es definida por Arendt como la característica de la existencia humana concerniente al estar entre los otros: inter-esse. ${ }^{22}$ Es decir, se trata de un atributo inclusivo o vinculativo. De ahí se explica que los actos y las palabras en las que se actualiza la libertad, necesitan de otros hombres para ser y mantenerse en el tiempo; es decir, la 'objetividad' de los actos libres depende de la presencia de otros hombres..$^{23}$ Por todo ello Arendt señala que la libertad y la acción nunca son posibles en la reclusión del individualismo:

Estar aislado es lo mismo a carecer de la capacidad para actuar,

${ }^{21}$ Ibid., p. 177.

${ }^{22}$ Cfr. F. Birulés, "Introducción: ¿Por qué debe haber alguien y no nadie?", en $\mathrm{H}$. Arendt, ¿Qué es la política?, 1997, Barcelona, Paidós, trad. R. Sala Carbó, p. 26. En este mismo orden de ideas Carmen Corral ha entendido que la libertad para Hannah Arendt no se limita a ser un sentimiento interior, sino una manifestación exterior: "la libertad es un fenómeno público, reside en el ámbito de lo plural, requiriendo la presencia y la participación activa de los demás". C. Corral, "La natalidad: la persistente derrota de la muerte", en F. Birulés, y M. Cruz, En torno a Hannan Arendt, 1994, Madrid, Centro de Estudios Constitucionales, p. 218.

23 "La publicidad de la esfera pública es lo que puede absorber y hacer brillar a través de los siglos cualquier cosa que los hombres quisieran salvar de la natural ruina del tiempo", nos dice nuestra autora en este sentido. H. Arendt, $L a$ condición humana, op. cit., p. 64. es una negación de la libertad. La acción y el discurso necesitan la presencia de otros no menos que la fabricación requiere la presencia de la naturaleza para su material $\mathrm{y}$ de un mundo en el que colocar el producto acabado. La fabricación está rodeada y en constante contacto con el mundo; la acción y el discurso lo están con la trama de los actos y palabras de otros hombres. ${ }^{24}$

Podemos decir, a partir de lo anterior, que la ciencia corre el riesgo de deshumanizarse, e imponer esta deshumanización a otros, si se aísla e impide un diálogo ético con la sociedad a partir del cual puedan descubrirse las coordenadas de la responsabilidad que le corresponden. La auténtica libertad para la actividad científica, parafraseando a José Pérez Adán, llega hasta donde todos los que nos beneficiamos de sus logros, podamos reconocer la responsabilidad por nuestros actos. ${ }^{25}$

\section{Conclusiones}

Hasta ahora hemos hecho un somero repaso por diversos lugares donde transcurren las preocupaciones prácticas en torno a la libertad y la ctividad

${ }^{24}$ Ibid., p. 211-2.

${ }^{25} \mathrm{Cfr}$. J. Pérez Adán, Sobre la libertad, la valía y la acción. Tres lecciones de Sociología, 2002, Valencia, Universidad de Valencia, p. 10-1. 
científica: los factores que defienden una identificación entre libertad y ausencia de límites, y los efectos que pueden suscitarse cuando estas tesis son llevadas a sus últimas consecuencias; igualmente, tratamos de vislumbrar los senderos que permitan superar estos dilemas.

Para concluir, podemos observar que el desafío vinculado a la definición de los contenidos de la libertad del científico, se traduce en una oportunidad para aproximar a la filosofía y a la ciencia: dos disciplinas que desde hace ya un largo período de tiempo, no vinculan sistemáticamente sus esfuerzos por comprender la realidad.

Concretamente, surge la ocasión de recuperar la serenidad en la reflexión práctica: la actitud de aquel que "acepta voluntariamente, como un límite lleno de sentido, lo que él no puede cambiar". ${ }^{26}$ Como enseñó Heidegger, sobre la serenidad debería asentarse la relación del ser humano con sus obras en una época como la actual, donde la reflexión meditativa pierde terreno frente al pensar calculador, y donde el poder oculto de la técnica moderna determina la relación del hombre con lo que realmente es. ${ }^{27}$ Dicho de otra manera, sin dejar de reconocer que sería necio arremeter ciegamente contra el mundo científico y técnico, la indagación acerca de los límites para la actividad del científico propone un aprovechamiento de sus resultados, manteniéndonos a la vez tan libres como para prescindir o desembarazarnos (loslassen) de ellos.

En definitiva, por medio de las indagaciones sobre la libertad que corresponde al científico, nos acercaremos a una situación donde, en palabras del propio Heidegger, podremos

decir sí al inevitable uso de los objetos técnicos y podemos a la vez decirles no en la medida en que rehusamos que nos requieran de modo tan exclusivo, que dobleguen, confundan y, finalmente, devasten nuestra esencia. ${ }^{28}$
${ }^{26}$ R. Spaemann, Ética: cuestiones fundamentales, 2001, Pamplona, EUNSA, trad. J. Yanguas, p. 119.
${ }^{27}$ Cfr. M. Heidegger, Serenidad, 1989, Barcelona, Ediciones del Serbal, trad. Y. Zimmermann, p. 18-23.

${ }^{28}$ Ibid., p. 27. 